\title{
Ballistic test investigation of hybrid rocket motor utilizing stearic acid biofuel with energetic additives for regression rate enhancement
}

Cite as: AIP Conference Proceedings 2339, 020174 (2021); https://doi.org/10.1063/5.0044504

Published Online: 03 May 2021

M. T. Ahmad, A. Jagannathan, R. Abidin, M. N. H. Noordin, W. M. H. Wan Ya'acob, A. Zhahir, and M. H. Azami

Challenge us.

What are your needs for periodic signal detection?

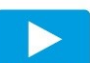

Watch

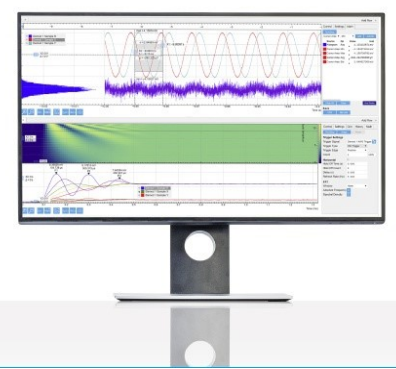

Zurich Instruments 


\title{
Ballistic Test Investigation of Hybrid Rocket Motor Utilizing Stearic Acid Biofuel with Energetic Additives for Regression Rate Enhancement
}

\author{
M T Ahmad ${ }^{1, a)}$, A Jagannathan ${ }^{1, b)}$, R Abidin ${ }^{1, c)}$, M N H Noordin ${ }^{1, d)}$, W M H Wan \\ Ya'acob $^{1 \mathrm{e})}$, A Zhahir, ${ }^{2, \mathrm{f}}$ and $\mathrm{M} \mathrm{H} \mathrm{Azami}{ }^{3, \mathrm{~g})}$ \\ ${ }^{1}$ Faculty of Enginering, National Defence University of Malaysia, Kem Sungai Besi, 57000 Kuala Lumpur, \\ Malaysia. \\ ${ }^{2}$ Department of Aerospace Engineering, Faculty of Engineering, Universiti Putra Malaysia, 43000 UPM Serdang, \\ Selangor, Malaysia. \\ ${ }^{3}$ Kulliyyah of Engineering, International Islamic University Malaysia, 53100 Gombak, Selangor, Malaysia.

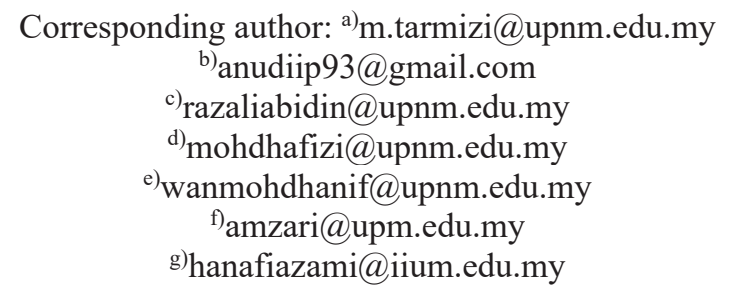

\begin{abstract}
This research evaluates a novel composition based on Stearic Acid (SA) wax fuel, enriched with aluminium and carbon nanotubes (CNT) for hybrid propulsion system by carrying out a ballistic test. Benchmarking the aluminium doped hybrid fuel with the SA wax fuel, the former reveal lesser viscosity which leads to relatively improved entrainment-aided combustion. In contrast to the pure SA fuel, fine aluminium powder doped hybrid fuels show solid-like behavior, and hence greater stability in the solid phase. The loading of ultrafine aluminium powder substantially improves the efficacy of fuel regression during ballistic firing.
\end{abstract}

\section{INTRODUCTION}

A vision of a simpler and safer hybrid engine propels space missions are envisaged by the progress in research and development of hybrid rocket fuel. This research is led by a National Defence University of Malaysia (NDUM) scientist along with his team in NDUM and collaborators from Universiti Putra Malaysia (UPM) and International Islamic University Malaysia (IIUM). This work presents the potential of applying aluminium doped hybrid fuel to improve the performance of hybrid engines.

Hybrid rockets have some advantages compared to conventional rocket fuel-based systems since it is the combination of solid fuel and fluidic oxidizer. These features are suitable alternatives to conventional systems for a variety of space applications such as, rocket launchers, rocket booster motor and upper stage launchers, high-end launch vehicles, orbital injection systems, and sub-orbits and sub-orbits of human space tourism. The favorable features are:

- Reduction to sensitivity to cracks and de-bonding of insulations.

- Combustion instability not affected by fuel.

- Higher specific impulse (Isp) as compared to solid rocket.

- Provides opportunity to apply throttling and start/restart capabilities.

Proceedings of Green Design and Manufacture 2020

AIP Conf. Proc. 2339, 020174-1-020174-10; https://doi.org/10.1063/5.0044504

Published by AIP Publishing. 978-0-7354-4091-3/\$30.00 
- Inherent safety from hazards of explosion due to propellant phase-separations.

- As compared to liquid rocket the engine design and manufacturing is simpler since it does not require regenerative cooling systems of combustion chamber and nozzles.

- Robust in selections of fuel/oxidizer and environmentally friendly.

There are also some limitations in hybrid propulsion system e.g. low regression rate and variations in combustion oxidizer/fuel mixture ratio. These limitations which cause lower combustion efficiency is due to the diffusion flame limited combustion model of hybrid propulsion.

The outcome of this research is to establish regression rate correlations of solid biofuel doped with energetic additives in a hybrid rocket motor. Not only will this research lead to publishable results, but this project will provide inexpensive access to low earth orbit with an environmentally acceptable, or relatively "green".

\section{RESEARCH BACKGROUND}

Hybrid rockets are one of the latest technologies in rocket propulsions. This is the most advanced system with better capabilities towards better green technology. It will be an alternative candidate to replace the liquid propellant rocket in the future. Rockets are primarily used as vehicle launchers to launch satellites into space. Several countries have a high potential for launching vehicles to space such Unites States, Russia, France, India, China, Japan, Israel, Iran and North Korea and other few countries have inherited the technology such as Great Britain, Ukraine, and South Korea with other nine European countries. This research is inspired to make Malaysia as one of the developed countries in Asia having competencies to be a part of this community. Hybrid rocket is simpler and more costeffective when compared to a liquid propellant rocket and less toxic waste and hazardous. The constraint on hybrid rocket propulsion systems of low regression rate poses a severe challenge. The overall sizing, geometric configuration and mass fluxes of the hybrid fuel ports are determined by the regression rate. The regression rate expression is hard to be obtained at different conditions because of the complexity of the combustion process and the variations of fuel regression rates with time and configuration.

\section{HYPOTHESIS}

The regression rate can be enhanced by utilizing non-polymeric solid fuel doped with energetic additives. The layer is hydro dynamically unstable in a gas flow environment leading to substantial droplet entertainment into the gas stream. The susceptibility of this fuel to this shear driven instability increases with decreasing viscosity and surface tension of the melted layer.

The energetic additives will encourage shorter ignition delay, shorter burning time and provide more complete combustion. This is because energetic particle materials in solid fuel provide higher energy release and higher density impulse. The CNT will provide higher thermal conductivity and structural rigidity for rocket propulsion applications.

\section{LITERATURE REVIEW}

A rocket engine uses fuel and a source of oxygen as propellants for forming its high-speed propulsive jet. The fuel and the oxidizer are mixed and exploded in a combustion chamber. The combustion generates hot exhaust which is passed through a nozzle to accelerate the flow and produce thrust. Most rocket engines are internal combustion engines that take their reaction mass from within the vehicle and form it into a high-speed jet, obtaining thrust in accordance with Newton's third law. Vehicles propelled by rocket engines are commonly called rockets. For a rocket, the working fluid is the hot exhaust produced during combustion. Liquid rockets and solid rockets are the two main categories of rocket engines. Recently, both the liquid rocket and the solid rocket is often used as a propulsion system in spacecraft and ballistic missiles. Liquid rocket needs to adjust both oxygen and fuel synchronously in order to maintain the oxygen-to-fuel ratio and the performance of the motor while changing the thrust. Solid rocket needs to redesign the configuration of the grain which is costly and complex and the thrust changing program depends on the setting before launching [1]. Compared to other types of jet engines, rocket engines are by far the lightest, and have the highest thrust, but are the least propellant-efficient because they have the lowest specific impulse. Rocket engines become more efficient at high velocities, due to greater propulsive efficiency. Since they do not require an atmosphere, they are well suited for uses at very high altitudes and in space. 
A hybrid rocket motor is a class of rocket motor in which the solid fuel is a polymeric material and oxidizer is a liquid or gaseous material. The application of hybrid rocket motor has been limited and further increases due to its high safety and lower environmental impact. However, this type of rocket motor has one major disadvantage which is low fuel burning rate and thrust. It was discovered that the members of the normal alkaline class of hydrocarbons that are solid at room temperature and has low surface tension and viscosity such as Paraffin waxes and polyethylene waxes are most suitable elements in the hybrid rocket fuel in order to produce high regression rate as compared to conventional hybrid fuel [2] A typical hybrid rocket motor proposes a number of advantages over the liquid rocket and solid rocket in terms of safety, throttling, environmental cleanliness, low cost and so on. It can be throttled easily by adjusting the oxidizer mass flow rate. Therefore, the hybrid rocket motor is highly suitable as the throttle-able rocket motor [3-10]. Figure 1 shows a typical hybrid rocket motor.

For the rocket propulsive principle, thrust is a propulsive force that is produced by imparting a change of moments to the exhaust combustion gases ejecting at the divergence section at the fuel surface. It is believed that employing fuel additives such as ammonium perchlorate (AP), ammonium nitrate (AN) and other nitroorganic compounds will lower the heat vaporization effectively. This will allow more solid fuel to combust into the flow of oxidizer. The addition of $20 \%$ of aluminum as additives in Hydroxyl Terminated Polybutadiene (HTPB) has increased the fuel mass flux by $70 \%$ over that of pure HTPB.

Doping fuel with metal additives is another approach to enhance the regression rate. The metal powder has the advantage to lower the heat vaporization of the fuel. Non-homogeneous fuel additives concentration is one of the ways to improve the non-uniformity of the local fuel regression rate. The unburned fuel causing slivers at the head and aft cap of the test motor. This will cause early port merging in the pre and aft section during combustion which results in instability during operation. The regression rate at the entrance of the port is relatively high due to the initial buildup of the boundary layer, called the "Blasius effect". At the entrance the boundary layer is thin, so heat transfer from the flame to the fuel surface is high, resulting in a high rate of fuel vaporization. From Marxman's Diffusion-Limited Analysis, the local regression rate is decreasing along the port length due to the decrease in convection heat transfer but at the far end downstream the enhancement of regression rate due to the increase in total mass flux from accumulated fuel from the surface.

In order to boost the mechanical strength, additives are required. Additives, however, typically have a lower rate of regression and weak properties of combustion. When considering the trade-off between maintaining the high regression rate of the paraffin-based fuel and meeting the mechanical strength criteria, the form and quantity of additives should be carefully selected. Additives such as PE, stearic acid (SA), and binder (ethylene vinyl acetate (EVA)) will increase the mechanical strength of solid fuel effectively [11-20]. The application of ammonium perchlorate (AP) to solid fuel was proposed as an effective method to improve the controllability of the staged hybrid rocket combustion efficiency, increase the reliability of the system, and achieve system simplicity. The addition of AP can provide better operating performance because it offers less variation of $\mathrm{O} / \mathrm{F}$, which means a high potential for maintaining the designed effluent temperature and requiring small throttling of secondary oxidizer mass flow [12]

The performance and properties of hybrid rocket fuels can be changed to some extent by adding solid additives such as metals and metal hydrides. Aluminum is one of the additives most researched for formulations of solid fuel. In the combustion chamber, the main advantages of aluminum are the relatively high oxidation heat and easy ignition. Additives such as aluminum powders are also considered as enhancing properties for their theoretical performance [21]. Including aluminum particles also helps to improve the engine's ideal O/F ratio [8]. The effects of other metal additives like Magnesium (Mg) and carbon black (C) on the rate of fuel regression in the HTPB fuel that significantly increase the rate of fuel regression. Nevertheless, there is no evidence of the effect of aromatic hydrocarbon anthracene $(\mathrm{C} 14 \mathrm{H} 10)$ on the HTPB fuel regression rate. The physical property and the thermal conductivity coefficient of $\mathrm{C} 14 \mathrm{H} 10$ and HTPB are similar because they are both hydrocarbons. Despite that, the addition of C14H10 can increase the density of the fuel, which may improve the density specific impulse of the motor. This is because the metal powder in the fuel may increase the radiative heat flux and improve the heat transfer coefficient of the fuel [14].

Many studies have shown that the addition of metallic ingredients as part of the additives improves energy density, flame temperature, chamber pressure and regression rate of solid fuel. Noticeably, the introduction of different metals as additives materials will give different performance for solid fuel. Aluminum, boron, and zirconium give the different specific impulse and combustion temperature in solid fuel performance. Aluminum additives, both on a micro- and Nano-scale have been shown to increase the regression rate of hybrid fuels while serving as a dense energy source. The addition of aluminum nanoparticle in solid fuel will reduce the O/F fuel ratio. Therefore, it will reduce the size of the oxidizer tank. The inclusion of aluminum particles within fuels can lead to 
an increase in specific impulse, volumetric heat of oxidation, adiabatic flame temperature, the heat of combustion, and radiative heat transfer [22]. By using a micro-scale aluminum particle, the regression rate can be increased by improving the radiative heat flux from the diffusion flame zone to the fuel surface as a result of the radiating metallic particulate matter and the higher gas-phase temperature [17]. Aluminum particles also increases the regression rate by the release of energy during metal oxidation. In addition, aluminum Nano-particle gives higher combustion efficiencies, better heat transfer, and a reduced ignition delay and burn time [23]. On the other hand, boron has taken interest from many researchers due to higher volumetric heat release than aluminum, but its use is limited due to its difficulty with ignition which can lead to low combustion efficiencies [22] According to [10], boron is a very attractive material in terms of energy density and burning rate. Moreover, Korotkikh et al. (2016) found that replacement of aluminum powder by boron and magnesium reduces the mass fraction of condensed products in the combustion chamber of the solid rocket motor. Magnesium is a readily available and affordable metal that has similar thermal capabilities to that of lithium aluminum hydride although it is slightly less reactive. It is easily ignited and burns with a hot flame, which can aid in the development of a liquid layer on the fuel surface [22]. It also can improve the high energy characteristic of solid fuel [17]. The performance of $\mathrm{Mg}$ is confirmed by the experimental result that $\mathrm{Mg}$ has lower grain than aluminum.

Multicomponent alloys such as high entropy alloys (HEAs) was never been reported as energetic additives with any propellants for hybrid rocket design. It is because, most of the reported investigations on HEAs focused on its structural properties $[6-7,9,16,19]$. However, owing to the extraordinary behaviours of these alloys, it is believed that the physical and chemical properties of this alloy can be explored by mixing different metals purposefully in equal proportion. It is reported that HEA nanoparticles have been proved to perform excellently in catalysis, chemical sensing, and biomedicine [15].

The cocktail effect of HEAs offers characteristic contributions of all elements involves as stated above. It is expected that the combination of multiples metals as an additive will provide the advantages of each element in improving the performance of the hybrid rocket. Besides, HEAs is reported as a new class of catalyst where it can provide a surface with many unique binding site conditions, resulting in the near-range distribution of associated adsorption energies [4]. As a result, sites with optimal properties will dominate catalytic activity within this distribution and provide the most vital catalyst sites. It has the near continuum distribution of associated adsorption properties due to its unique binding sites environment of the surface property. Due to these reasons, HEA nanoparticles can be utilized as high energy materials nanocatalyst in solid rocket propellants. The high surface area additives help to attain fast ignition and short particle burn duration while promoting high conversion efficiency within the residence time of a combustor [5].

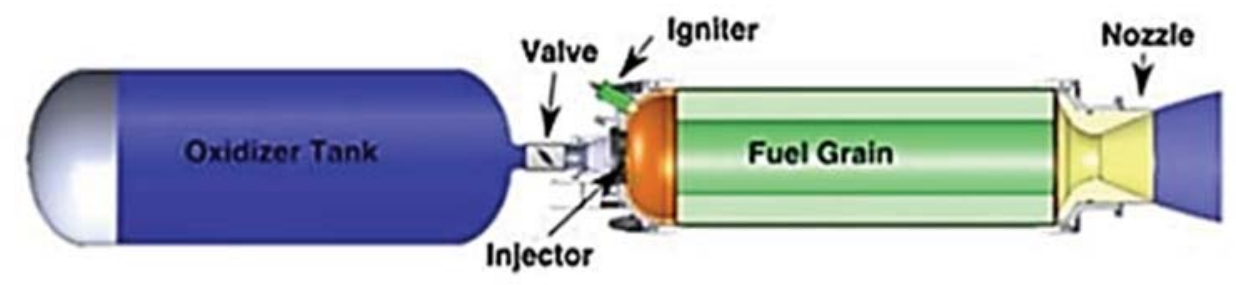

FIGURE 1. Hybrid Rocket Motor Schematics.

\section{MATERIALS AND METHODS}

The methodology of the investigation is as follows:

a. Determine the rocket chamber temperature and chemical composition for any propellant combination using thermochemical calculations (NASA CEA program).

b. Design a hybrid propellant rocket engine consisting of combustion chamber, injector, igniter, nozzle and oxidiser system by considering the propellant combination heat transfer and cooling characteristics.

c. Design a hybrid rocket motor based on the propellant combination, burning rate laws and grain design.

d. Design, build and test hybrid rocket motor to measure thrust coefficient, specific impulse, , characteristic exhaust velocity and compare to theoretical calculations

e. Performance analysis of hybrid rocket engine. 


\section{Chemical Equilibrium Analysis}

The Chemical Equilibrium Analysis was executed by using Chemical Equilibrium Software Cpropep-Web. Cpropep can compute chemical equilibrium for a fixed temperature and pressure points, adiabatic flame temperature, frozen and shifting equilibrium rocket performance evaluation.

This highly useful thermochemical software allows the user to evaluate the theoretical performance of a solid (or liquid) rocket propellant. As such, it is particularly useful for checking the viability of possible propellant formulations. As well, it allows the user to quickly determine the most effective ratios of ingredients to achieve desired performance, from a theoretical perspective.

GUIPEP is primarily a chemical equilibrium solver, that is, it balances the chemical equations relating the propellant reactants and products by a method known as "minimization of Gibbs free energy". The ingredients (reactants) defining the propellant are transformed adiabatically and irreversibly to reactions product constituents in the amounts fixed by equilibrium relations, chamber pressure, and mass balance at a reaction temperature fixed by the available energy of reaction. The resulting set of products provides the basis for computation of thermodynamic properties from which performance parameters are determined by an iterative process to account for changing product properties and composition.

Input is simply a list of propellant ingredients (and the mass of each), as well as chamber pressure and nozzle exit pressure. Solver output includes combustion temperature, isentropic exponent, molecular weight of products, exhaust temperature and composition, specific impulse, and ideal expansion ratio.

TABLE 1. Propellant Data.

\begin{tabular}{ccccc}
\hline Propellant type & \multirow{2}{*}{ Symbol. } & units & \multirow{2}{*}{ SA } & 0\% SA +27\%AL \\
CNT 3\%
\end{tabular}

\section{Preparation of the Hybrid Rocket Fuel}

The constituents of developed fuels included a blend of Stearic acid as the base fuel along with fine aluminium powder all procured through commercial suppliers. The physiochemical properties of constituent fuel and additives are summarised in Table 1. All components of hybrid fuel were used without any further purification or modification. The average particle size of aluminium-additive is different due to commercial availability.

TABLE 2. Fuel Formulations.

\begin{tabular}{ccc}
\hline Properties & $\begin{array}{c}\text { SA } \\
\mathrm{CH}_{3}\left(\mathrm{CH}_{2}\right) 16 \mathrm{COOH}\end{array}$ & Al \\
\hline $\begin{array}{c}\text { Molecular mass } \\
(\mathrm{g} / \mathrm{mol})\end{array}$ & 284.484 & 3000 \\
Density $\left(\mathrm{g} / \mathrm{cm}^{3}\right)$ & 0.89 & $2.70 \mathrm{~g} / \mathrm{cm}^{3}$ \\
$\begin{array}{c}\text { Average particle size } \\
\text { Melting point }\left({ }^{\circ} \mathrm{C}\right)\end{array}$ & - & - \\
Boiling point $\left({ }^{\circ} \mathrm{C}\right)$ & $69.6^{\circ} \mathrm{C}$ & $660.32{ }^{\circ} \mathrm{C}$ \\
\hline $\begin{array}{c}\text { Standard enthalpy of } \\
\text { combustion }(\mathrm{kJ} / \mathrm{mol})\end{array}$ & $376^{\circ} \mathrm{C}$ & $2470{ }^{\circ} \mathrm{C}$ \\
\hline
\end{tabular}


The fuel formulations for the proposed rocket fuel are shown in Table 2. These compositions are used to prepare fuel for ballistic performance analysis, where they are poured into molds of $185 \mathrm{~mm}$, outer diameter $40 \mathrm{~mm}$ and port diameter $15 \mathrm{~mm}$. The inner walls are covered with grease to facilitate grain removal after curing. The solidification process is carried out by turning the mold into an ice bath using an electric motor to rotate the mold. The motor delivery process is carried out in several steps. Only a small amount of molten fuel is poured slowly and allowed to drain before it prevents bubble formation and deficiencies. Preparations of prepared grains are performed and the grains are stored overnight for curing. Similar processes are repeated to prepare all test fuels. Table 3 is the specification of the test motor.

TABLE 3. Hybrid Rocket System Specifications.

\begin{tabular}{|c|c|c|c|c|}
\hline & & Composition & & $\begin{array}{c}70 \% \text { Stearic Acid Wax, } 27 \% \\
\text { Aluminum, 3\% Carbon nanotubes }\end{array}$ \\
\hline & & Grain Configuration & & Cylindrical \\
\hline & & Number of Ports & & 1 \\
\hline Combustion & & Initial Port Diameter & $\mathrm{mm}$ & \\
\hline \multirow[t]{15}{*}{ Chamber } & & Grain Length & $\mathrm{mm}$ & \\
\hline & & Grain Diameter & $\mathrm{mm}$ & \\
\hline & & Oxidizer-to-Fuel Ratio & & 8.034 \\
\hline & Nozzle & Material & & Aluminum \\
\hline & & Shape & & Conical Nozzle \\
\hline & & Expansion Ratio & & 3.88 \\
\hline & & Throat Diameter & $\mathrm{mm}$ & 10 \\
\hline & & Exit Diameter & $\mathrm{mm}$ & 44 \\
\hline & & Fuel Mass & $\mathrm{kg}$ & 1.43 \\
\hline & & Chamber Pressure & psi & 203 \\
\hline & & Thrust & $\mathrm{N}$ & 348 \\
\hline & & Oxidizer Flow Rate & $\mathrm{kg} / \mathrm{s}$ & 0.01 \\
\hline & & Thermocouple & ${ }^{\circ} \mathrm{C}$ & 185 \\
\hline & Oxidizer & & & Nitrous Oxide \\
\hline & $\begin{array}{c}\text { Supercharge } \\
\text { Gas }\end{array}$ & & & Nitrogen \\
\hline \multirow[t]{4}{*}{ Oxidizer Tank } & \begin{tabular}{|c|} 
Loaded \\
Oxidizer Mass \\
\end{tabular} & & $\mathrm{kg}$ & 0.65 \\
\hline & Tank Mass & & $\mathrm{kg}$ & 4.6 \\
\hline & \begin{tabular}{|c|} 
Propellant Tank \\
Pressure
\end{tabular} & & psi & 14 \\
\hline & $\begin{array}{c}\text { Initial Tank } \\
\text { Pressure }\end{array}$ & & psi & 754 \\
\hline
\end{tabular}

\section{RESULTS AND DISCUSSIONS}

\section{Motor Tests and Post-Analyses}

The Static test was carried out at UPNM Rocket Static Test Stand. The Test data were fully captured by the Arduino data acquisition and control system. Prior hot-fire test, standard cold-flow tests were conducted to verify the control system, ignition firing sequence, and to characterize the oxidizer flow rate and pressure drop in the feed line. 


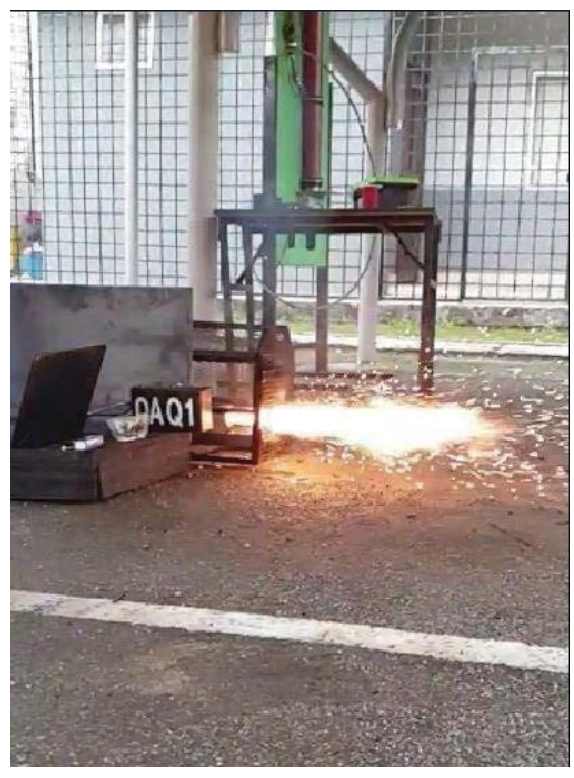

FIGURE 2. Hybrid Rocket Test.

Figure 2 shows the test motor being fired on a static test rocket stand. The hybrid rocket motor was able to produce a peak thrust of $348 \mathrm{~N}$ with combustion chamber pressure of 14 bars as shown in Fig. 3.

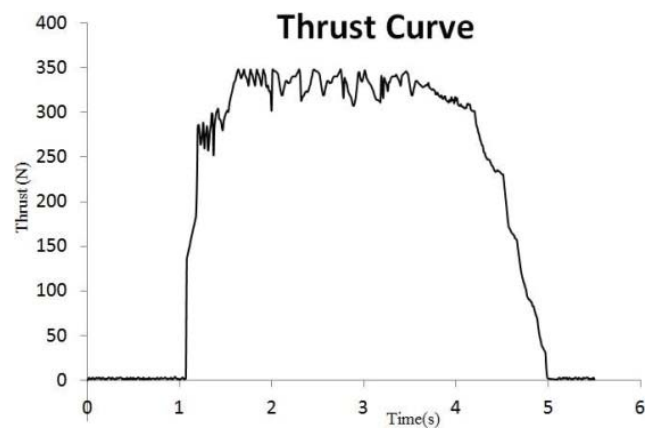

(a)

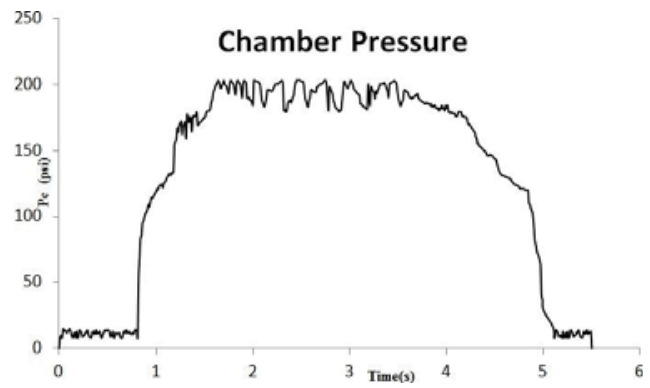

(b)

FIGURE 3. (a)Time History Hybrid Rocket Motor: Thrust, (b) Chamber Pressure 


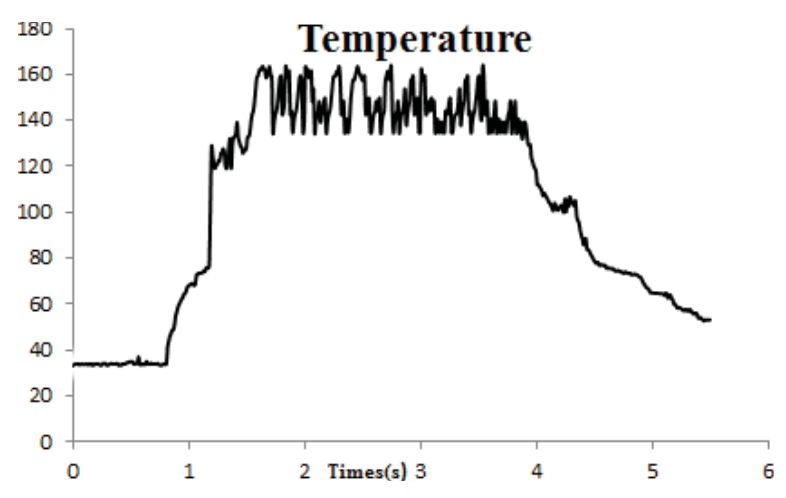

(c)

FIGURE 3. (c) Temperature.

In Fig. 3(b), it can be noticed that the chamber pressure builds up progressively and then begin to reach a steady state. While the steady-state mean of 203 psig was noted with the pressure oscillation of \pm 3 from the mean value. The thrust profile of Figure 3(a), of the firing, showed above man thrust $348 \mathrm{~N}$. The thrust produced builds up and then starts to level off, the same phenomena as observed in pressure-time history (Fig. 4).

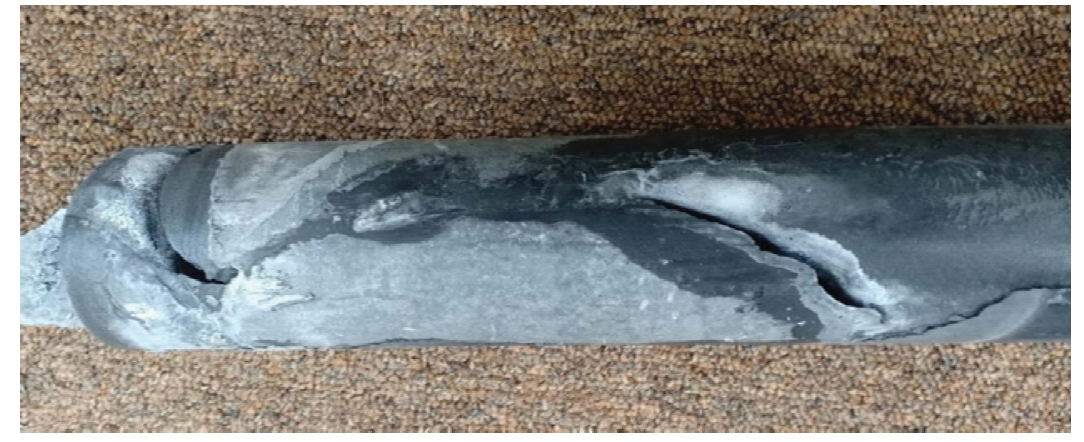

FIGURE 4. Shows the Post-Burning of the Fuel Grain Cartridge.

\section{INJECTOR NOZZLE COLD FLOW PATTERN TEST}

Before fire tests were conducted, a fill test along with a cold flow test of the injector manifold was conducted. The purpose of the fill test was to verify the amount of liquid nitrous oxide that the supply tank can fill the flight tank. From the tank was able to release nitrous oxide. The results of the cold flow test through the injector shows that at nitrous oxide released into atmospheric pressure, the mass flow of oxidizer through the injector (Fig. 5) is approximately $0.01 \mathrm{~kg} / \mathrm{s}$. shows the flow pattern of the nitrous exiting the injector during the cold flow test. It can be visually seen and confirmed in and by the apparent axial showerhead that the nitrous oxide leaving. This verifies the CFD model and initial flow pattern expectations of the injector. 

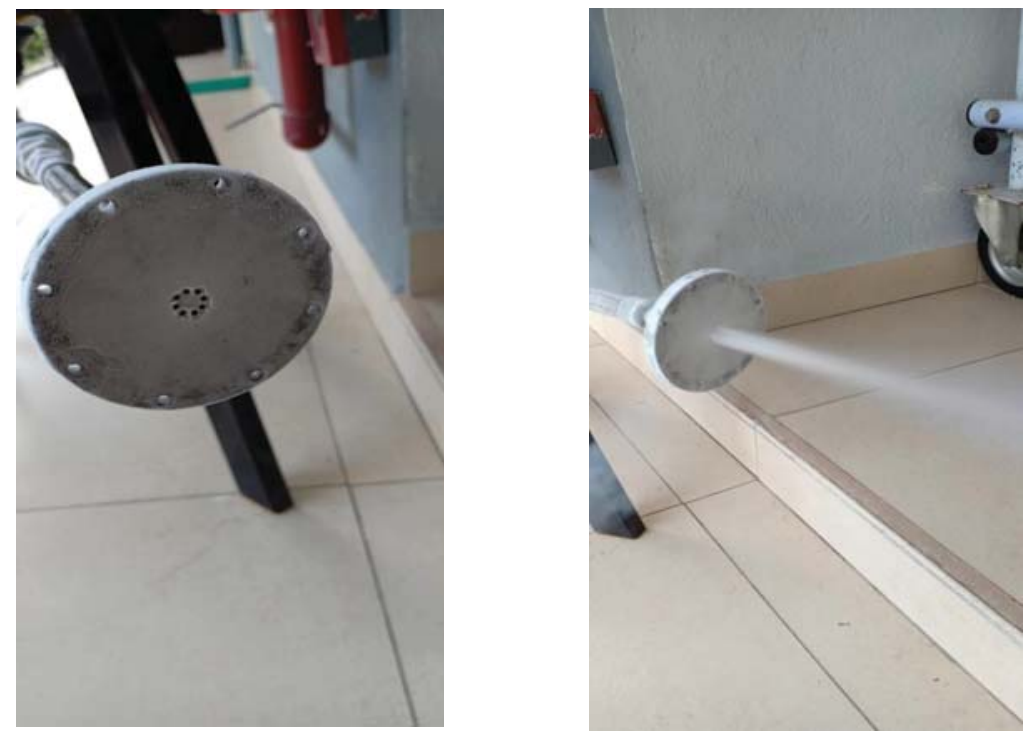

FIGURE 5. Nitrous Oxide Injector Cold Flow Test.

\section{CONCLUSIONS}

The core objective of this research was to design, develop, and test a hybrid rocket motor a throttled hybrid rocket motor for use on scientific-sounding rockets. An extensive survey of hybrid rocket propulsion was performed to determine potential propellants for the hybrid rocket propulsion system and to characterize critical components of a typical motor. Through this process, a propellant combination of liquid nitrous oxide as the oxidizer was selected due to their inherent advantages described in Chapter Nitrous oxide self-pressurizing behavior in an enclosed storage compartment eliminates the incorporation of a complex turbine-driven pump in the feed system, but with installing an additional pressuring system. In control volume, nitrous oxide is delivered to the combustion chamber under its pressure with the aid of nitrogen which increases the oxidizer tank pressure. The model is based on existing work but includes additional features such as the gaseous nitrous oxide blowdown process. This self-pressurizing nitrous oxide delivery system provides a more realistic description of the decay of the motor thrust than using a constant oxidizer mass flow rate.

The oxidizer feed and injection system have allowed for a complete design and construction with safety rated components. Drag inflow passages and insertion losses through controls were reduced drastically by reducing the number of fittings and components from the tank to the injector. Also, atomization and mixing of the oxidizer were improved using an axial showerhead injection method. Despite all these tremendous efforts to establish this foundation there is still work to be completed. Continued fire testing will provide insight into the yet fully understood phenomena occurring and establish a much more accurate transient model of the nitrous oxide tank; these models will enable more accurate performance predictions.

This project taught the benefits of experimentation. Most of the solutions sought did not have clear answers. Trouble was often encountered in finding simple conceptual answers to questions and instead high fidelity over specific analysis had to be developed. Initial experiments were all accomplished using everyday materials to qualitatively solve issues particularly those of injector flow pattern. Every increase in fidelity and quality of the experiment provided substantial additional information used to design and build the oxidizer motor; however, without the smaller and much simpler experiments to give guidance, early efforts made towards the final design would have been misguided. Care must be taken to ensure all conclusions are rooted in scientific fact and found with sound reasoning. When doubt comes to mind one must not underestimate the value of simple basic experiments and calculations from the engineering fundamentals to provide guidance. Validation and verification of all decisions and designs ensure optimum results. 


\section{ACKNOWLEDGEMENTS}

The authors acknowledge Centre of Research and Innovation Management, National Defence University of Malaysia for the Short-term Grants and lab facilities. Special thanks to those who contributed to this project directly or indirectly.

\section{REFERENCES}

1. Zhao, Yu, Liu, Zeng and Wang, Aerosp Sci Technol. 1, 1-10 (2018).

2. Shrivastava, IREASE. 35-41 (2018).

3. Cai, Li and Tian, Acta Astronaut. 128, 286-294 (2016).

4. Batchelor, T. A. A., Pedersen, J. K., Winther, S. H., Castelli, I. E., Jacobsen, K. W and Rossmeisl, J, Mater. Sci. 3, 834-845 (2019).

5. Carmicino and Sorge, J Propul Power. (2015).

6. Gludovatz, George and Ritchie, JOM. (2015).

7. Guo, Wang, Luo, Li, Su, Guo and Fu, Mater. Des. (2015).

8. Jens, Cantwell and Hubbard, Acta Astronaut. 128, 119-130 (2016).

9. Juan, Tsai, Tsai, Lin, Wang, Yang and Yeh, J. W, Intermetallics. (2015).

10. Jung, Yun, Kim, Park and Kwon, "Performance evaluation of ramjet fuel grains with boron and magnesium additives" (Joint Propulsion Conference, 2018).

11. Korotkikh, Glotov and Sorokin, "Effect of Metal Additives on the Combustion Characteristics of High-Energy Materials" (Tomsk; Russian Federation: MATEC Web of Conferences, 2016).

12. D. Lee and Lee, J Propul Power. 33(6), 1581-1588 (2017).

13. Li, Lin, Zhu, Wu, Yu, Wei and Wu, Aerosp Sci Technol. 82-83, 620-627 (2018).

14. Li, Tian, Yu and Cai, Acta Astronaut. 105(1), 95-100 (2014).

15. Luo, Sankar, Beale, He, Kiely, Bruijnincx and Weckhuysen, Nat. Commun. (2015).

16. Miracle, Miller, Senkov, Woodward, Uchic, and Tiley, Entropy. (2014).

17. Pal and Kumar, Thermochim. Acta. (2017).

18. Sankaran, "Fundamentals of Hybrid Rocket Combustion and Propulsion" (2007).

19. Senkov, Wilks, Miracle, Chuang and Liaw, Intermetallics. (2010).

20. Sun, Tian, Li, Yu, and Cai, Acta Astronaut. 119, 137-146 (2016).

21. Veale, Adali, Pitot and Bemont, Acta Astronaut. 151, 864-873 (2018a).

22. Veale, Adali, Pitot and Bemont, Acta Astronaut. (2018b).

23. Veale, Adali, Pitot and Brooks, Acta Astronaut. (2017). 